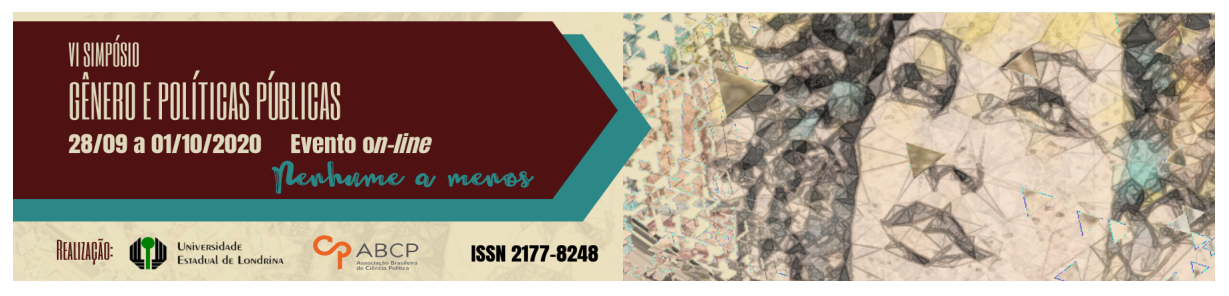

\title{
MÃES NA GRADUAÇÃO: política e maternidade nas universidades públicas do Brasil
}

\author{
Tatiana Viana de Oliveira1; Mirian Alves de Souza²
}

\begin{abstract}
Resumo
$\mathrm{O}$ artigo trata dos desafios de conciliar maternidade e universidade, focando a graduação, a partir da pesquisa etnográfica desenvolvida junto ao Coletivo de Mães da UFF, do qual fiz parte (2016- 2019) e, que buscou visibilidade, apoio às mães e a implementação de políticas públicas específicas à permanência na universidade. Relaciona-se a um movimento de "politização" da maternidade, propondo novas linguagens e negociações. Os movimentos feministas levaram a importantes reflexões sobre a sujeição das mulheres (inclusive maternidade), bem como sobre um possível lugar de emancipação delas. A produção antropológica sobre o tema da maternidade cresce a cada dia e, a partir do trabalho de campo desenvolvido (2018-2019), propõe-se uma reflexão sobre os desafios enfrentados em conciliar maternidade e estudar em uma universidade pública no Brasil.
\end{abstract}

Palavras-chave: maternidade; política; universidade.

\section{UNDERGRADUATE MOTHERS: politics and motherhood in public universities in Brazil}

\begin{abstract}
The article deals with the challenges of reconciling maternity and university,

1 Mestranda do Programa de Pós-graduação em Antropologia da Universidade Federal Fluminense PPGA/UFF, Graduação em Direito (UERJ, 2014) e em Antropologia (UFF, 2019), tatianavoliveira@gmail.com.

22 A pesquisa foi orientada, no âmbito da graduação, por Mirian Alves de Souza, mirian.uff@gmail.com, doutora e mestre em Antropologia PPGA/UFF e professora do Departamento de Antropologia e do Programa de Pós- graduação em Justiça e Segurança da Universidade Federal Fluminense.
\end{abstract}

GT 18 - Políticas públicas de gênero no Brasil do século XXI: avanços e desafios 
focusing on graduation, based on the ethnographic research developed with the UFF Mothers Collective, of which I was a part (2016-2019) and which sought visibility, support for mothers and implementation of public policies specific to university stay. It is related to a movement to "politicize" motherhood, proposing new languages and negotiations. Feminist movements have led to important reflections on the subjection of women (including motherhood), as well as on a possible place for their emancipation. Anthropological production on the theme of motherhood grows every day and, based on the fieldwork developed (2018-2019), it is proposed a reflection on the challenges faced in reconciling motherhood and studying at a public university in Brazil.

Keywords: motherhood; politics; university.

\section{Apresentação - a construção do campo etnográfico}

O trabalho a ser apresentado consiste em uma pesquisa etnográfica desenvolvida junto ao Coletivo de Mães da Universidade Federal Fluminense (UFF), do qual faço parte, desde o segundo semestre de 2016. E que consiste em uma associação de mães alunas da universidade, que busca encontrar soluções efetivas que viabilizem o retorno e permanência de mães estudantes à \na universidade, através da formação de uma rede de apoio ${ }^{3}$ mútuo entre as integrantes que as auxilie nos desafios enfrentados para conciliar a maternidade e os estudos (em alguns casos, também trabalho), para terminarem seus respectivos cursos e, finalmente, prosseguirem na vida profissional.

O coletivo também busca medidas institucionais que favoreçam a permanência destas mães, tal como a existência de um espaço que acolha seus filhos (Ludoteca) enquanto elas estiverem em atividades acadêmicas, permissão de acesso livre e alimentação das mães alunas e seus filhos ao Restaurante Universitário ("bandejão"), combate ao assédio moral, dentre outros.

O meu interesse pelo assunto adveio da minha própria maternidade. Após o primeiro mês de aula no Curso de Antropologia da UFF, em junho de 2013, descobri que estava grávida. Com o

${ }^{3}$ A categoria rede de apoio aqui diz respeito a pessoas ou estabelecimentos que auxiliem nos cuidados de uma criança, como familiares, amigos, babás, creches, etc. 
nascimento de minha filha, tranquei o curso por dois anos (tempo máximo permitido), retornei em 2016 e ali se instaurou um grande dilema, a cada início de período, sobre continuar ou abandonar curso. Era muito difícil conciliar maternidade, estudos, trabalho e vida social, e também sentia uma enorme culpa em me afastar da minha filha para trabalhar e estudar. Assim, eu fazia poucas matérias por período e só conseguia estudar depois que ela dormia. A sensação era de que eu estava sempre em débito com minha filha, estudos e casamento. Não participava da vida social acadêmica e estava sempre atrasada. Concluí o curso ao final de 2019.

Em 2016, fui convidada por uma amiga, Angela, para participar do Coletivo de mães da UFF, que estava se organizando, inclusive a partir da rede social Facebook. Aceitei o convite, mas eu não conseguia acompanhar as atividades.

Ali se iniciava a formação de uma rede de apoio entre mães alunas da UFF, com revezamento no cuidado com os filhos (para as mães poderem assistir às aulas). Eram poucas participantes, cerca de quatro ou cinco $^{4}$. Mas, no final de 2017, o Coletivo ficou menos movimentado uma vez que suas integrantes principais tomaram caminhos diferentes. Foi a primeira fase do coletivo.

Em maio de 2018, o grupo voltou a ter uma nova movimentação, a partir da inciativa de uma nova integrante, Elena. Solicitei meu ingresso no grupo que ela criou de WhatsApp, pretendendo ser mais participativa e fazer do Coletivo meu contexto etnográfico. Relembrando William Foote Whyte, é possível mudar alguma coisa escrevendo sobre ela (WHYTE, 2005). Assim, o Coletivo era onde estavam, segundo Evans Pritchard, minha personalidade, minha cabeça e meu coração (PRITCHARD, 2005).

4 Comentário de Melissa: “Uma questão importante era que nenhuma de nós tinha família em Niterói, então, não tínhamos uma rede para nos auxiliar, para pegar as crianças na escola, ficar com elas durante as aulas, etc. Então, formamos essa rede uma para a outra, nesse processo eu e Angela ficamos mais próximas (nossos filhos têm idade similar) e Luciana e Ivana depois vieram a morar juntas." 
Muitas mulheres levam mais tempo do que outras para concluírem seus cursos de graduação em razão da maternidade, situação que pode as levar ao abandono do curso. As razões são de muitas ordens: cuidados dos filhos, dedicação a atividades acadêmicas, deslocamento para a faculdade, necessidade de trabalhar (para algumas), dificuldades financeiras (sobretudo quando a mãe é única provedora financeira), problemas de moradia, dificuldades psicológicas e afetivas (como cansaço, falta de apoio familiar, depressão, assédio, dentre outros).

Neste sentido, nos últimos anos, vêm se formando, em âmbito nacional, coletivos de mães universitárias, a fim de mudarem esta realidade, na busca da construção de uma rede de apoio mútuo e para reivindicar políticas públicas voltadas para o apoio e permanência destas mães durante o período de estudo na universidade.

Na introdução do livro Arenas Públicas - por uma vida associativa (2011), Fabio Reis Mota, Felipe Berocan e Daniel Cefai consideram as associações como "fóruns híbridos" que não podem ser definidas senão a partir de suas complexidades e capitais simbólicos, que podem fazer emergir questões que até então não faziam parte da discussão no plano social, gerando coletivos até então inexistentes, a partir da formação de identidades coletivas e do engajamento pessoal, em verdadeira contribuição para a formação da "experiência do mundo, de si e do outro, e para emergência de normas éticas, jurídicas e políticas de um bem-viver coletivamente" (MOTA; BEROCAN; CEFAI, 2011, p. 51).

Segundo Heloisa Regina Souza, no artigo desenvolvido a partir do livro Convertirse em madre: etnografia del tempo de gestación, de Elixabete Imaz Martínez (2015), a maternidade contemporânea é vista como ponto de inflexão de algumas mulheres (no caso, a classe média), que rearticulam suas biografias femininas, trazendo à tona movimentos e dilemas que compõem os intensos processos de subjetivação no tornarse mãe. E é então sobre o aspecto político da maternidade que desenvolvi a pesquisa: a associação de mães alunas que reivindicam visibilidade e apoio da seara pública (no caso, do meio acadêmico) e que 
se insurgem contra a omissão do Estado para consecução de medidas que facilitem a conciliação dos cuidados maternos dos filhos e formação acadêmica.

\section{Metodologia utilizada}

A pesquisa foi desenvolvida utilizando-se a observação participante: fui integrante do Coletivo entre 2016-2019 e, a partir de 2018, participei de reuniões, confeccionei documentos, o representei publicamente e auxiliei na tomada de decisões.

Realizei também entrevistas diretas, utilizei artigos de jornal, documentários e redes de relacionamento como Facebook e WhatsApp.

Sendo assim, por cerca de três anos, participei do Coletivo em questão e, por um ano e cinco meses, acompanhei e participei efetivamente das atividades como pesquisadora.

\section{A (re)politização da maternidade}

No censo de 2012, o Instituto Nacional de Estudos e Pesquisas Educacionais Anísio Teixeira (Inep) demonstrou que a maioria do corpo discente nas graduações brasileiras é do sexo feminino. Foram apontadas 3.286.415 matrículas femininas, contra 2.637.423 masculinas. A mesma informação foi confirmada, em 2018, pelo mesmo Instituto, bem como pelo Instituto Brasileiro de Geografia e Estatística (IBGE) e pela Coordenação de Aperfeiçoamento de Pessoal de Nível Superior (Capes). A informação também consta em reportagem da Revista Crescer sobre mães voltarem a estudar depois do nascimento dos filhos, e conclui que"se a sala de aula é predominantemente feminina, ela é potencialmente materna" (INTI, 2019) 5 .

5 5INTI, Simone. “Mães na universidade - elas falam dos desafios de voltar a estudar depois dos filhos. Revista crescer, 25 de mar. 2019. Disponível em: https:// revistacrescer.globo.com/amp/Meumomento/noticia/2019/03/meumomento-maes-na-universidade-elas-falam-dos- 
O artigo do Inep, por sua vez, apontou que as entrevistas feitas ressaltaram as dificuldades encontradas por mães na conciliação família/ trabalho, uma vez que as funções do homem são, no máximo, de "ajuda" e, portanto, dependem de atos de boa vontade, permitindo, assim, que eles possam optar por se dedicarem exclusivamente ao trabalho, deixando às mulheres as tarefas do lar e, em consequência, do cuidado e educação dos filhos.

Além disso, segundo o IBGE, em 2016, as mulheres dedicaram aos cuidados de pessoas e/ ou afazeres domésticos cerca de $73 \%$ a mais de horas do que os homens (18,1 horas contra 10,5 horas), qualquer que seja o grupo de idade observado. Inep e o IBGE concluíram que as mulheres ainda ganham menos que os homens, mesmo quando desempenham as mesmas atividades, e também são o principal ator responsável pela criação da prole e cuidados dolar.

Margarete Mead, na pesquisa que originou o livro Sexo e Temperamento em três sociedades primitivas, em 1935, procurou mostrar que características femininas e masculinas (chamadas "temperamentos") são padrões culturais que moldam os comportamentos dos integrantes de determinado grupo social e passados de geração a geração. Em consequência, o comportamento é que produz a diferenciação nas personalidades existentes entre os sexos.

Sua pesquisa se baseou em três grupos sociais distintos da Papua, Nova Guiné e concluiu que os comportamentos (e, portanto, os temperamentos) existentes ou não, entre homens e mulheres, bem como a responsabilidade de cuidados dos filhos, são construções sociais que poderiam variar abruptamente em diferentes grupos sociais.

Lucila Scavone observa que, a maternidade passou, ao longo dos últimos setenta anos, a ter um aspecto relacional e foi investida de significados diferentes. E, não obstante os avanços nas elaborações simbólicas sobre tal tema, ainda hoje as mulheres são as maiores

desafios-de-voltar-estudar- depois-dos-filhos.html. Acesso em: 17 nov. 2019. 
responsáveis pelos cuidados da prole (Scavone, 2001).

Heloisa Regina Souza alerta que para uma (re)politização da maternidade, que vem a embaralhar certos domínios historicamente separados, no Ocidente: ação política e vida pessoal, público e privado, maternidade e paternidade, natureza e cultura. (SOUZA, 2015). Vemos hoje um vigoroso ativismo materno, identificado também pela composição de diversos espaços de discussão e debates, em redes sociais digitais, rodas de conversa e grupos de militância engajados com a transformação de suas realidades locais. E é sob este aspecto, o da militância, que se desenvolvem os coletivos de mães universitárias. ${ }^{6}$

A pesquisa desenvolvida, em 2016-2017, por Silvana Maria Bitencourt que originou o artigo Cuidar ou ser cuidada? Os dilemas e os efeitos da maternidade em uma universidade brasileira, sobre mães universitárias em Cuiabá aponta que a maternidade exige dedicação e tempo e, ainda hoje, o cuidado com os filhos e as tarefas domésticas são pensados como um espaço "naturalmente" da mulher. Assim, conciliar o tripé que envolve graduação, maternidade e a subjetividade leva ao acúmulo de funções, fazendo com que a mulher deixe de lado os cuidados de si, além de ser julgada como descumpridora de seu dever, o que acarreta sofrimento e sentimento de culpa, o que leva à perda de saúde e problemas como depressão, estresse, obesidade, hipertensão, diabetes, subnutrição (BITENCOURT, 2017), acentuadas ainda mais quando as acadêmicas não possuem companheiros para dividir tais obrigações, situação que estão de acordo com relatos colhidos na presente pesquisa:

Elena, mãe do Coletivo da UFF, colocou: "A sociedade não tem espaço pra mãe, sobretudo quando é mãe solteira, pois para continuar

\footnotetext{
6 Identifiquei coletivos de mães nas seguintes universidades: UNIVERSIDEDADE FEDERAL DO RIO DE JANEIRO (UFRJ), na UNIVERSIDADE FEDERAL RURAL (COMPAMA/ UFFRJ), na UNIVERSIDADE FEDERAL DE SANTA CATARINA (UFSC), na UNIVERSIDADE FEDERAL DE GOIÁS (UFG), na UNIVERSIDADE DE BRASÍLIA (Unb), na UNIVERSIDADE FEDERAL DE SÃO PAULO (USP), na UNIVERSIDADE FEDERAL DE SANTA MARIA e NA UNIVERSIDADE FEDERAL DO RIO GRANDE DO SUL.
} 
sobrevivendo, não tem política pública ou ações sociais para seguir adiante com seu filho. (...) O pai pode esquecer que a criança existe, a vida segue. (...) Para a mulher, a vida se torna tão carregada, tão pesada que é muito mais fácil abortar nas próximas gestações."

E Mayara (Coletivo de mães da UFRJ) disse que "o peso da maternidade, até pela própria sociedade, é muito maior que o peso da paternidade. As cobranças, as responsabilidades, tudo que acontece em relação à criança, na maioria das vezes, recai sobre a mãe. Parece que nós, por sermos mulheres, sempre podemos e devemos ter dedicação exclusiva sobre tudo que envolve os filhos, essa cobrança já não ocorre com tanto peso em cima do homem. Eu vejo isso, tanto na minha maternidade, quanto na das minhas amigas mães. Eu, por exemplo, sou mãe 'solo'7, para poder estudar preciso montar uma estrutura de apoio gigante. O pai das minhas filhas também estuda na mesma faculdade que eu, e não precisa de de nenhuma estrutura para estudar, a estrutura dele sou eu, alguém já falou sobre essa desigualdade? Ninguém. Porque todos acham que isso é uma responsabilidade minha, porser mãe."

\section{Os coletivos de mães universitárias no brasil}

Os coletivos de mães universitárias, em geral, possuem como objetivos centrais a criação de uma rede de apoio mútuo, dentro da universidade, propondo reflexões quanto aos desafios na conciliação de cuidados dos filhos e estudos, e busca a construção de diálogos junto à instituição a que se vinculam para implementação de políticas públicas que apoiem a permanência das mães estudantes na universidade ${ }^{8}$. As demandas de cada coletivo podem variar em cada relativamente aos

\footnotetext{
${ }^{7}$ Mãe solo é uma categoria nativa, recorrentemente utilizada e tem o sentido de ser mãe sozinha, que não conta com a ajuda do pai da criança em sua manutenção e cuidados. 8 A título de exemplificação, identifiquei coletivos de mães nas seguintes universidades: Universidedade Federal Do Rio De Janeiro (UFRJ), na Universidade Federal Rural (COPAMA/ UFFRJ), na Universidade Federal De Santa Catarina (UFSC), na Universidade Federal De Goiás (UFG), na Universidade De Brasília (Unb), na Universidade Federal De São Paulo (USP), na Universidade Federal De Santa Maria e na Universidade Federal Do Rio Grande Do Sul. A maior parte dos coletivos encontrados são formados somente por mães, caso da UFF, UFRRJ, UFRJ, UFSC e da UFG. Outros contam com a presença dos pais também, caso do COPAMA (UFRRJ).
} 
demais, de acordo com a necessidade das alunas, o perfil da instituição e de já haver, ou não, políticas instituídas em benefício das mães.

Mayara, do coletivo de mães da Universidade Federal do Rio de Janeiro (UFRJ), aponta: "Eu acho que o intuito do coletivo foi esse, saber que não sou só eu que tem esse problema e que outras mães têm esse problema e vivem essa problemática e que a gente tinha que se reunir e cobrar da universidade políticas pra nossa permanência porque eu voltei em 2015 mas quantas mães não podem voltar ou desistem de vez e isso é um problema muito grande. (...) Eu sempre fui envolvida politicamente mas não de forma profunda. Desde meu ensino médio sempre participei de atos, sempre estive presente, mas eu me aprofundei mais mesmo com a questão da maternidade. Acho que ela que deu o impulso para eu poder me envolver de fato na questão política."

Assim, tais coletivos trazem à tona, por um lado, o questionamento de se o cuidado dos filhos deve se ater realmente ao ambiente doméstico (e, em específico, à mulher), a partir do momento em que elas passam a atuar, cada vez mais, em atividades no âmbito público e, por outro, atentam para o fato de que, ainda que seja uma realidade imposta às mães, deve a sociedade garantir efetivamente, através do estabelecimento de políticas públicas, soluções para que as mães desempenhem os diversos papéis sociais que surgem.

Se hoje podemos tecer algumas importantes reflexões sobre "o lugar da mãe" na família e na sociedade, há muito que avançar sobre o "lugar do pai" e o papel do Estado na criação de uma criança, convidando todos atores sociais a participarem, pois, como diz um antigo ditado africano, "é preciso uma aldeia inteira para cuidar de uma criança".

\section{O coletivo de mães da UFF}

Como já exposto, a formação de coletivos de mães universitárias apresenta-se como um mecanismo legítimo de associação para desvelar a realidade vivenciada silenciosamente por mães universitárias. 
Mota, Berocan e Cefai, no Livro Arenas Públicas (2011), consideram que as associações são os nós das redes sociais, que criam variadas frentes de aliança e oposição. As etnografias feitas em associações, neste sentido, consistem em etnografias morais e políticas, eis que expõem, nos seus contextos de experiências específicas, as disputas travadas no âmbito social, na tentativa de transformar os jogos de poder. E, a cada situação, vemos emergir uma complexidade de associações que, com suas exposições e desenvolvimento, nas arenas públicas, desempenham papel de destaque para definição do ponto do conflito e da causa que se pretende defender, ora dando continuidade, ora possibilitando a ruptura dos jogos sociais.

No último questionário para mapeamento das mães alunas da UFF, proposto por participantes do próprio Coletivo de Mães da universidade (2019), no qual 26 das 30 integrantes responderam, foi verificado que as idades variam de 21 a 44 anos, tendo a maioria entre 20 e 30 anos. As idades dos filhos variam entre 0 e 9 anos de idade. São ainda variados os cursos acadêmicos escolhidos: Antropologia, Produção Cultural, Turismo, Arquivologia, Ciências Sociais, Estatística, Pedagogia, Biblioteconomia. Pouco menos da metade é casada e divide tarefas com seus companheiros, $34,6 \%$ declarou que conta com alguma parceria de familiares (não incluídos aqui os pais dos filhos) e 15\% declarou morar sozinha com seus filhos.

Quanto às demandas principais do coletivo, 50\% declarou que precisaria com frequência da Ludoteca, $43,3 \%$ declarou que precisaria apenas ocasionalmente e $7,7 \%$ não precisa. E, relativamente ao uso do "bandejão", 66,7\% declarou que precisa do bandejão e 33,3\% declarou que não precisa.

Apesar de não ter constado do questionário, há também grande diversidade cultural e de classe econômico-social no Coletivo. Assim, discussões raciais e econômicas, como racismo, desemprego e ausência de apoio financeiro, por vezes, são frequentes entre as mães.

O coletivo de mães da UFF foi criado em 2016, a partir do evento 
"Roda de Conversa: Mães e Universidade combinam?", realizado na UFF, em 14/07/2016, pela estudante de Psicologia da universidade, Luciana, que, quando engravidara, teve que sair da moradia estudantil possível, pois ali não se admite crianças. Após o evento, ela e Melissa, pósgraduanda no mestrado em Sociologia, decidiram criar um grupo no WhatsApp e no Facebook ${ }^{9}$, convidando outras mães a se juntarem para discussão e troca de experiências sobre a maternidade na universidade. A partir dali se estabeleceram demandas comuns e formou-se uma pequena e eficiente rede de apoio entre si, que, para Angela, foi fundamental para sua permanência na universidade. Interessante notar que elas não buscaram muitos diálogos com a instituição, pois acreditavam que UFF nada fazia por falta de vontade ${ }^{10}$.

A segunda fase do coletivo se inaugurou com quando Elena ingressou. Em maio de 2018, ela fez um comentário numa publicação da UFF, em sua página no Facebook, que felicitava as mães pelo dia das mães. Elena tinha uma filha com cerca de cinco anos, que a acompanhava à UFF alguns dias na semana. Sua base familiar estava em Saquarema, estado do Rio. Assim, para continuar na graduação, precisava levar sua filha para a UFF. Com o apoio da professora Celeste, solicitou sua inclusão no Facebook e então decidiu criar um novo grupo de WhatsApp. Passou a ser a mãe mais atuante, liderando o grupo e representando o coletivo por todo o restante do ano de 2018, em reuniões, perante setores da UFF, e-mails e direcionamentos das pautas.

Nesta fase, Elena, conseguiu marcar a primeira reunião com o então Pro- Reitor de Assuntos Estudantis, Leandro, em que foram determinadas muitas diretrizes para obtenção da Ludoteca. Em resumo,

\footnotetext{
${ }_{9}$ Comentário de Melissa: “Uma questão importante era que nenhuma de nós tinha família em Niterói, então, não tínhamos uma rede para nos auxiliar, a pegar crianças na escola, ficar com elas durante as aulas, etc. Então, formamos essa rede uma para a outra, nesse processo eu e Angela ficamos mais próximas (nossos filhos têm idade similar) e Luciana e Ivana depois vieram a morar juntas."

10 Segundo Angela, "Quanto mais a gente depende das instituições, mais a gente se torna dependente delas, sabe, menos a gente consegue se organizar de forma autônoma, e aí, as outras meninas que estavam antes tinham uma perspectiva politica mais parecida com a minha. Isso foi uma coisa que fez com que a gente conseguisse se unir de uma forma e tentar ações mais autônomas, sabe. A gente nunca creditou que a UFF fosse dar nada pra gente."
} 
o coletivo deveria formalizar sua existência para dialogar com a instituição e deveria apresentar uma pauta de reivindicações, enumerando os benefícios da universidade em atender tais demandas. Tais exigências requeriam dedicação e pesquisa, e isso sobrecarregava mais as integrantes. Elena propôs a formação de pequenas comissões de trabalho, desenvolvidas por via virtual, mas poucas mães aderiram.

Com a voracidade do grupo, muitas mães, já assoberbadas com seus desafios diários, saíram do grupo. Porém, a maioria das integrantes nada falavam e que gerava, por parte das mais atuantes, pedidos de ajuda, desabafos sobre as dificuldades, conclamando as demais mães, o que gerava novas discussões, tensões e mais mães saíam do grupo.

Eu torcia para que o grupo caminhasse sem minha participação, a fim de manter um distanciamento maior para a pesquisa, mas era nítida a ausência de força de trabalho e acabei encarregada de mapear quais mães precisavam da sala, a frequência, se já tinham trancado ou abandonado a faculdade em razão da maternidade, se tinham sofrido assédio. Deveria também procurar outros coletivos de universitários para trocar informações e buscar modelos que já funcionavam. ${ }^{11}$

Produzimos vasto material, que foi entregue no prazo estipulado, mas a resposta não veio conforme esperado: deveríamos aguardar. Foi muito decepcionante, pois o final de um semestre significava um retrabalho de tudo que tinha sido elaborado naquele período e a possibilidade de perda de confiança das integrantes que dependiam de medidas.

A adesão para reuniões também era sempre pouca. Além disso, as reuniões ocorriam normalmente no pilotis do bloco $\mathrm{H}$ do campus do Gragoatá, em meio à circulação de outros estudantes - não havia um

\footnotetext{
11 Como disse Melissa: "A partir das nossas trocas pudemos perceber que o que acontece com as mães é uma anti-assistência estudantil, todas as frentes da universidade que existem para dar suporte aos estudantes são retiradas das estudantes que são mães. Para as que se tornam mães no meio do curso são ainda maiores, com os empecilhos criados para a execução do Regime Excepcional de Aprendizagem. Isso repercute diretamente na evasão escolar dessas mulheres, que são impelidas a abandonar o curso pela retirada de toda a assistência estudantil, aliada às demandas inerentes da maternidade."
} 
lugar reservado, protegido do tempo e de barulho, dificuldade que se acentuava mais quando se levava uma criança, o que aumentava o sentimento de marginalidade.

Ao final do segundo semestre de 2018, a única medida conquistada de fato foi uma autorização temporária, por 90 dias, para entrada de mães lactantes com seus bebês no restaurante universitário, proibida a alimentação das crianças ali. Tal medida não surtiu muito efeito: os servidores alegavam que desconheciam a medida e, além disso, a partir de 10/10/2018, o "bandejão" fechou para todos os alunos, em razão de greve.

Ao final do ano, o coletivo estava desmobilizado. Elena engravidou e retornou para Saquarema. As demais integrantes estavam envoltas de tarefas pessoais e acadêmicas típicas fim de semestre.

O ano de 2019 se iniciou com a ciência da proposta de emenda constitucional (PEC) n. 241 que previa o corte e congelamento na educação, por vinte anos. Entendíamos que a implementação de medidas, como a Ludoteca, seria inviabilizada, por falta de verbas e que precisávamos pensar em novas propostas. Sem líderes, sem perspectivas.

A situação mudou em março, quando o coletivo foi convidado para participar da roda de conversa "Mulheres na Graduação", que aconteceria no dia 20. Fui convidada a falar juntamente com Carla, que se sentia insegura, mas acreditava que era uma grande oportunidade de o coletivo ganhar visibilidade. Assim, aceitei o convite e elaborei um texto para apresentar, com ajuda de Elena.

Tivemos êxito em pontuar as demandas principais e oferecemos propostas efetivas, que solicitariam investimentos mais baixos. Apesar do baixo público, ganhamos apoio e simpatia. Carla se destacou como representante do grupo e foi convidada para reuniões com esferas institucionais. Iniciava-se a terceira fase do coletivo.

Carla, estudante de Produção Cultural e mãe de gêmeos, se 
consolidou como a líder do Coletivo, em 2019: "Entro no coletivo em 2017, a partir do apelo da Elena buscando mães para se unirem (...) Me afastei na época da aprovação do regulamento da Ludoteca por não concordar com a presença de homens e também por achar que o coletivo não estava seguindo logística nenhuma de organização. Voltei por acaso, as coisas começaram a acontecer, os convites e fomos buscando organizar..."

Após este dia, o coletivo ganhou novo fôlego, apoio e mais visibilidade. Carla continuou o legado de Elena e foi além, tentando aplicar uma logística de organização e demandas com setores da UFF12. Marcou reuniões, formalizou pautas prioritárias, abriu formulários para novos mapeamentos. Novas mães se animaram. Novas portas se abriram, jornais nos procuraram. Participou de entrevista na tv Alerj, em jornais como O Dia, O Globo e a própria assessoria de imprensa da $\mathrm{UFF}^{13}$ nos procurou. Ela também geria o grupo do Facebook e criou, no WhatsApp, o Coletivo Nacional de Mães (que já existia no Facebook), de maneira a favorecer trocas com integrantes de outros coletivos e artigos atuais sobre maternidade, em âmbito nacional, o que favoreceu uma retomada do contato com outros coletivos.

Ela também fundou o NIEM - Núcleo interseccional Estudos da Maternidade, do qual também fiz parte, composto por mães de diversos coletivos, com a finalidade de realizar uma coleta de dados e demandas, em âmbito nacional.

No entanto, a ampliação das redes externas de apoio e a maior visibilidade do Coletivo da UFF, aumentou a carga de trabalho, sem aumento da participação das integrantes, o que gerava mais sentimento de injustiça, mais cobranças e novas discussões. Repetiam-se os mesmos

1212 "Entro no coletivo em 2017, a partir do apelo da Elena buscando mães para se unirem (...) Me afastei na época da aprovação do regulamento da Ludoteca por não concordar com a presença de homens e também por achar que o Coletivo não estava seguindo logística nenhuma de organização. Voltei por acaso, as coisas começaram a acontecer, os convites e fomos buscando nos organizar...".

13 Disponível em: http://www.uff.br/?q=noticias/09-10-2019/ser-mae-na-uffconquistas-e-desafios-na-construcao-de-uma-universidade-de-

todos\&fbclid=IwAR00MIEn2joJ0cNUjcRERjQK200gHVM220VWifxKM4e2IqUHfYj171 hH4s8. 
desgastes: pedidos de maior adesão, não aceitação de críticas por quem não contribuía, saídas de integrantes. Neste período, éramos cerca de 30 mães mas apenas três ou quatro atuavam com frequência. A continuidade do coletivo era uma preocupação constante.

No dia 21/10, aconteceu o I Colóquio, na semana acadêmica. O evento contou com a participação de representantes dos Coletivos de Mães da UFF, da UFRJ e da UFRRJ, do NIEM, bem como representantes de setores da UFF e foi lançado, pelo GT de Mulheres na Ciência (que contou com a colaboração do NIEM), o documento "Propostas de políticas de apoio à maternidade para universidade", que visa servir de base para todas as universidades nacionais. Finalmente as demandas das mães estavam firmadas numa carta de compromissos, em âmbito nacional, salientando-se que algumas pautas ali expostas já foram implementadas pela UFF. Sem dúvida, foi um evento sem precedentes para o Coletivo, pois gerou ainda mais visibilidade e congregou diversos setores da instituição.

No entanto, ali também constatou-se que a continuidade do Coletivo continuava incerta, pois eu e Carla estávamos nos formando e, em consequência, sairíamos da UFF, não havendo quem sinalizasse que daria continuidade. Assim, nascia a institucionalização das políticas de permanência de mães na universidade e possivelmente morria a terceira fase do Coletivo, sem perspectiva da inauguração de uma nova fase.

\section{Conclusão}

Na presente pesquisa, a maternidade pode ser observada a partir de uma perspectiva mais política, na medida em que mães buscam reconhecimento de suas existências no meio institucional acadêmico e dos desafios que enfrentam diuturnamente para se manterem na universidade e cuidarem de seus filhos, reivindicando apoio da sociedade e concessão de políticas públicas por parte do estado.

A partir do interesse partilhado em ver suas demandas 
atendidas, parte destas mães se associa e forma coletivos, com o intuito de se organizarem e exigirem implementação de políticas que reconheçam a igualdade, bem como a singularidade de suas experiências. Estes coletivos também se apresentam, portanto, como mecanismos eficazes para explicitarem o "nó social" consubstanciado, por um lado, na exigência de uma maternidade exercida com dedicação intensiva para a criança e, por outro, na possibilidade de uma mãe desempenhar vários outros papéis sociais, sem que o Estado brasileiro forneça meios eficazes para tanto.

Adriana Vianna e Juliana Farias, no artigo “A guerra das mães: dor e política em situações de violência institucional" (2011), atentam para o fato de que, longe de ser um fato isolado, o acionamento da condição de mãe como elemento de autoridade moral nos atos políticos nos fala de trânsitos relevantes em cenários contemporâneos: nestes contextos, a "casa" é levada para a seara pública, através do que seria o seu "centro exemplar" simbólico, a própria maternidade, e donde se destacam duas unidades simbólicas - as mães e o Estado (VIANNA; FARIAS, 2011).

A emergência destes coletivos de mães, assim, expõe as disputas travadas, no âmbito social, e permite que, pessoas possam ultrapassar diferenças, ganhando um reconhecimento legal e político, transformando relações e os jogos de poder até então estabelecidos.

\section{Referências}

BITENCOURT, Silvana Maria. Cuidar ou ser cuidada? Os dilemas e os efeitos da maternidade em uma universidade brasileira. Seminário Internacional Fazendo Gênero 11 \& 13th Women's Worlds Congress. Anais [...]. Florianópolis, 2017, ISSN 2179-510X.

CAPES. Mulheres representam 60\% dos bolsistas da CAPES. Disponível em: https://www.capes.gov.br/36-noticias/9375-mulheresrepresentam-60-dos-bolsistas-da- capes. Acesso em: 15 nov. 2019.

CEFAI, Daniel Mello; SILVA, Marcos Antonio da; MOTA, Fabio Reis; 
VEIGA, Felipe Berocan. Arenas Publicas: por uma etnografia da vida associativa. Niterói: ed. UFF, 2011.

FOOT WHYTE, William. Sociedade de Esquina: A estrutura social de uma área urbana pobre e degradada. Ed. Jorge Zahar. Rio de Janeiro, 2005 [1943].

IBGE. Coordenação de População e Indicadores Sociais. Estatísticas de gênero: indicadores sociais das mulheres no Brasil. Complemento 1, n. 38. Rio de Janeiro, 2018. Disponível em: https://biblioteca.ibge.gov.br/index.php/bibliotecacatalogo?view=detalhes\&id=2101551. Acesso em: 26 nov. 2019.

INEP. Mulheres são maioria na Educação Superior brasileira. Disponível em: http://portal.inep.gov.br/artigo//asset_publisher/B4AQV9zFY7Bv/content/mulheres-sao- maioriana-educacao-superior-brasileira/21206. Acesso em: 15 nov. 2019.

MEAD, Margaret. Sexo e temperamento em três sociedades primitivas. São Paulo: Perspectiva, 1999.

PRITCHARD, Edward Evan. Bruxaria, Oráculos e Magia entre os Azande. Rio de Janeiro: Jorge Zahar Ed., 2005.

SCAVONE, Lucila. A maternidade e o feminismo: diálogo com as ciências sociais. Cadernos pagu, Campinas, v. 16, p. 137-150.

SOUZA, Heloísa Regina. Tornar-se mãe: maternidades contemporâneas no País Basco. Revista Civitas, Porto Alegre, v. 15, n. 2, p. 342-349, 2015.

VIANNA, Adriana; FARIAS, Juliana. A guerra das mães: dor e política em situações de violência institucional. Cadernos Pagu, Campinas, v. 37, p. 79-116, 2011.

WHYTE, William Foote. Sociedade de Esquina. Ed. Jorge Zahar. Rio de Janeiro.

YEARLEY, Carole. Motherhood as a rite of passage: an anthropological perspective. In: MIDWIFERY PRACTICE SERIES: Core Topics 2, chapter 2, p. 23-37. Palgrave, London, 1997. 